\title{
PROBLEMAS DE LEGITIMACIÓN EN LOS PROCESOS CONSTITUCIONALES ${ }^{1}$
}

\author{
POR \\ IGNACIO TORRES MURO \\ Catedrático habilitado de Derecho Constitucional \\ Universidad Complutense
}

\section{NTRODUCCIÓN. LEGITIMACIÓN Y PROCESOS CONSTITUCIONALES}

Nuestro propósito es el de analizar todos los procesos que tienen lugar ante el Tribunal Constitucional español desde la perspectiva de los sujetos que pueden participar en los mismos, activando, por así decirlo, el funcionamiento de este órgano.

\section{Problemas, no certezas}

El uso de la palabra problemas en el título de este trabajo intenta orientar al lector en el sentido de que el objeto principal del mismo son las disfuncionalidades del sistema, las dudas, los puntos controvertidos. No es que no se vaya a

${ }^{1}$ Correspondo con este texto a la amable invitación del profesor Torres del Moral para publicarlo en esta revista. Debo advertir, sin embargo, al lector que se trata de un resumen apretado de las tesis que se mantienen con la extensión necesaria en mi libro La legitimación en los procesos constitucionales, Editorial Reus, Madrid 2007. Al mismo remito a quienes deseen manejar un tratamiento mucho más completo de los problemas. 
intentar hacer una exposición clásica de todos los matices de la legitimación en los procesos constitucionales, pero también es verdad que la atención se va a fijar deliberadamente en aquellos asuntos en los que no existe una opinión pacífica, tanto en la jurisprudencia como en la doctrina.

Sin renunciar a construir un estudio general de la legitimación en los procesos constitucionales, es cierto que centraremos nuestros esfuerzos en las patologías del sistema, entre otras cosas porque partimos de la convicción de que es en ese terreno en el que se pueden ofrecer algunas sugerencias para el futuro, que contribuyan a ir perfilando mejor una problemática de cuya importancia creemos sinceramente que no se puede dudar.

\section{Una concepción no rigurosa del término legitimación. Legitimación preferentemente activa}

De acuerdo con nuestra manera de ver las cosas entenderíamos por legitimación la capacidad de activar, o poner en marcha, un proceso constitucional concreto, lo que, por otro lado, nos conduce a excluir de nuestro análisis, en principio, la llamada legitimación pasiva, que también se da en alguno de ellos, y sobre la que quizás sea necesario decir algo en algún momento. Seguimos así los planteamientos de un sector de la doctrina española que, ante las dificultades para extraer un concepto preciso de legitimación en los procesos constitucionales, ha hablado de que ésta «se reduce... a un derecho a acceder a la jurisdicción constitucional que otorga la posibilidad de iniciar un proceso y de disponer sobre la actividad alegatoria y sobre la pretensión procesal $»^{2}$ y de que, más simplemente, «la legitimación... se identifica con la capacidad para ser parte principal en un procedimiento constitucional suscitado ante el Tribunal Constitucional» ${ }^{3}$.

Esta falta de «rigor» permite que abordemos fenómenos a los que muy difícilmente podría aplicárseles un concepto clásico de legitimación, y ni siquiera el revisado que acabamos de ver, como el papel de los jueces y tribunales en las cuestiones de inconstitucionalidad. Creemos que así se enriquece el análisis, dado que las categorías más laxas pueden utilizarse, con mayor facilidad, en esa variedad de procesos a través de los cuáles se manifiesta la voluntad del Tribunal Constitucional.

2 J. García Roca, El conflicto entre órganos constitucionales, Madrid 1987, p. 66.

3 R. Canosa Usera, Legitimación autonómica en el proceso constitucional, Madrid 1992, p. 42. 


\section{Procesos constitucionales}

En lo que si podemos ser estrictos y rigurosos es en la delimitación de los procesos constitucionales objeto de nuestro estudio: se trata ni más ni menos que de los previstos en la LOTC.

Agrupándolos en esa división tripartita de las funciones del Tribunal que se refleja en el índice de este trabajo, podemos hablar de que el TC, en cuanto juez de la constitucionalidad, se pronuncia en los recursos de inconstitucionalidad, las cuestiones de inconstitucionalidad, y las declaraciones sobre la constitucionalidad de los tratados internacionales; en cuanto Tribunal de conflictos sus instrumentos son los conflictos de competencia, positivos y negativos, los conflictos en defensa de la autonomía local, los conflictos entre órganos constitucionales, y las impugnaciones del art. 161.2 CE; como juez de los derechos fundamentales, es el recurso de amparo el proceso tipo.

\section{EL TRIBUNAL COMO JUEZ DE LA CONSTITUCIONALIDAD}

El control de la constitucionalidad de las normas es, sin duda, la competencia "estrella» de las jurisdicciones constitucionales, la que prácticamente justifica su existencia, y la que no puede faltar si estamos hablando de un fenómeno de este tipo.

Es por eso que, en sus diferentes manifestaciones, el problema de decidir quien activa los mecanismos que sirven a la misma es uno de los más importantes que se plantean, cuando de instituir y desarrollar un sistema de justicia constitucional se trata.

\section{El recurso de inconstitucionalidad}

Lo que nos interesa es un problema concreto: el de quien puede poner en marcha este mecanismo de control de constitucionalidad, conscientes de que aquel que tenga atribuida por el ordenamiento dicha facultad dispone de uno de los poderes más importantes dentro del Estado constitucional, el de cuestionar, ante su más alta instancia jurisdiccional en materia de garantías constitucionales, la adecuación a la norma suprema de alguno o algunos preceptos de una con rango de ley, es decir, producto, en principio, de la sacrosanta potestad legislativa mediante la que se expresan los representantes del Pueblo soberano. 


\subsection{Solamente instituciones básicas y por ser vos quien sois}

El primer rasgo que salta a la vista respecto a la legitimación en el recurso de inconstitucionalidad en España es que la misma se ha reservado a instituciones, órganos, o fracciones de órganos, de lo que se ha dado en llamar Estado-aparato.

En resumen, nada de acción popular y, en el caso de que exista un derecho o interés legítimo vulnerado por actos de aplicación de una ley, queda siempre abierta la vía de la autocuestión de inconstitucionalidad.

Sentado este carácter ciertamente limitado de la legitimación en España, es preciso hacer referencia a que la misma, en el diseño de la CE y la LOTC, y en la interpretación que del mismo ha dado el TC en su jurisprudencia, no responde a la existencia de un interés propio del sujeto legitimado sino, más bien, a su carácter de entes de especial importancia en el sistema constitucional.

\subsection{Los órganos legitimados en concreto}

a) El Presidente del Gobierno. La facultad del más fuerte

Los arts. 162.1 a) CE y 32.1 LOTC comienzan citando entre los legitimados al Presidente del Gobierno, reconociendo así, una vez más, que nos encontramos ante la figura más importante de nuestro sistema jurídico constitucional, y que su posición dentro del ejecutivo es especialmente preeminente, al igual que es máxima la relevancia que tiene en nuestro régimen político, hasta el punto de que se haya hablado (Rubio) de uno de tipo "cancilleresco».

Ha sido subrayado acertadamente como, dado que en el sistema constitucional español, a través de los mecanismos de investidura y de confianza, la correlación entre el titular del ejecutivo y la mayoría parlamentaria está asegurada, resulta difícil que el Presidente del Gobierno presente recurso de constitucionalidad contra normas con rango de ley procedentes de las Cortes Generales, de modo que la práctica enseña que todos esos recursos lo son contra normas de las Comunidades Autónomas.

\section{b) El Defensor del Pueblo. Una legitimación inadecuada}

Es patente que nos hallamos ante un órgano auxiliar que, inspirado en tradiciones escandinavas cuyas enseñanzas se superaron en un arriesgado ejercicio de voluntarismo, que ha llevado a unos resultados ciertamente llamativos, tiene en la atribución de esta facultad, absolutamente inusual en el derecho com- 
parado, una de sus competencias más importantes y más delicadas, que lo cierto es que, hasta ahora, los titulares del órgano han usado con prudencia, precisamente porque, con toda probabilidad, han sido conscientes de lo anómalo de una situación en la que un "Ombudsman» puede nada menos que cuestionar, entre otras, las actividades legislativas de su órgano matriz, las Cortes Generales. A pesar de algunos magros ejemplos extranjeros, no nos cabe duda de que la atribución de esta facultad resulta ciertamente chocante, por no decir claramente inadecuada. Estas argumentaciones conducen a preguntarse si no estará el Defensor perdiendo más de lo que gana al poder interponer el recurso de inconstitucionalidad, y las fuertes polémicas que algunas de sus actuaciones en este ámbito han provocado demuestran que, en cierto modo, se le pone en una situación extremadamente difícil cuando se solicita su intervención, situación de la que resulta imposible salir airoso y que provoca un desgaste considerable, desgaste que lo convierte, contra lo que debería ser su tendencia dominante, en un órgano político más, dedicado a argumentar, constitucionalmente, eso sí, contra productos de la potestad legislativa que, por definición, son polémicos.

El TC sigue esta orientación al decir que se debe reconocer la legitimación del Defensor del Pueblo para interponer recursos de inconstitucionalidad «sin sujetarla a límites ni condiciones objetivas de ningún tipo» (STC 150/1990, de 4 de octubre, FJ 1), pues "con independencia de la cualidad del Defensor del Pueblo como alto comisionado de las Cortes Generales para la defensa de los derechos comprendidos en el Título I, su legitimación al respecto ha de entenderse en los mismos términos y con la misma amplitud que la del resto de los sujetos contemplados conjuntamente en los arts. 162.1 a) y 32.1 LOTC (STC 274/2000, de 15 de noviembre, FJ 2 «in fine»).

c) Cincuenta Diputados y Cincuenta Senadores. Minorías políticas y Tribunal Constitucional. Los Presidentes de las Cámaras

Siguiendo estas recomendaciones del padre de la justicia constitucional (Kelsen) la mayoría de los sistemas que instauran un sistema concentrado, en el que sea posible interponer el recurso directo de inconstitucionalidad, reconocen la legitimación de un grupo más o menos amplio de parlamentarios.

Así lo hacen, desde luego, la CE [art. 161.1 a)] y la LOTC [art. 32.1 c) y d)], en el caso de España, al prever que cincuenta Diputados y cincuenta Senadores pueden abrir esta vía de cuestionamiento de la constitucionalidad de una norma, y así sucede en dos de los ordenamientos que hemos llamado a la comparación, el francés y el alemán, siendo la excepción italiana considerada, incluso 
por gran parte de la doctrina de aquel país, como una situación relativamente anómala que quizás conviniera superar ${ }^{4}$.

En ese contexto más amplio puede entenderse perfectamente que se dote a las minorías más significativas, aquéllas que pueden identificarse con la oposición $^{5}$, de la posibilidad de activar el control de constitucionalidad por parte del TC. Parece como si esa fuese la manera natural de prolongar la controversia que se ha producido en las Cámaras, si los opositores son capaces de dotarla de contenido constitucional; es decir, si es algo más que una diferencia de criterios sobre problemas de mera oportunidad política, y afecta a los fundamentos del sistema, que han sido recogidos por la norma fundamental.

Es cierto que existe lo que podíamos llamar prejuicio a favor del control concreto de constitucionalidad y crítica del abstracto, sobre todo cuando es promovido por minorías parlamentarias, hasta el punto de propugnar su supresión y considerar la situación italiana como la más correcta.

Por ello, partiendo de la base de que en todos los procesos constitucionales tiene una fuerte influencia el factor político, también creemos que hay someter a dura crítica el tópico, en el que, por supuesto, hay algo de verdad, de la preferencia del control concreto. Sin perjuicio de remitir a Montilla ${ }^{6}$ conviene recordar que el mismo no carece tampoco de inconvenientes, principalmente el de sus muchas lagunas, demostradas por la experiencia italiana, pues son abundantes las normas que solo pueden presentarse ante el TC en un juicio abstracto de constitucionalidad, ya que no son reglas llamadas a aplicarse por la jurisdicción ordinaria. Este hecho es la mejor base para propugnar que se combinen los controles abstracto y concreto, de modo que queden cubiertas todas las posibilidades de aparición de normas contrarias al texto constitucional.

El Tribunal Constitucional ha ido perfilando, poco a poco, los rasgos de este tipo de legitimación, empezando por afirmar que nos hallamos ante una agrupación ocasional o ad hoc de parlamentarios «que se unen al solo efecto de impugnar la validez constitucional de una Ley. La agrupación surge sólo de la concurrencia de voluntades en la decisión impugnatoria y sólo tiene existencia jurídica como parte en el proceso que con esa impugnación se inicia, en el cual los Diputados o Senadores no actúan en rigor como litis consortes, sino

${ }^{4}$ En Italia sobre estos problemas cabe remitir a G. D’Orazio Opposizione parlamentare e ricorso al giudice delle leggi, Milán 1996; y F. Bientinesi «Il ricorso delle minoranze parlamentari alle Corti costituzionali», en Giuriprudenza Costituzionale (1996), pp. 2727 y ss.

5 Como dice Sánchez Navarro «el concepto de minoría política (por lo general parlamentaria) puede identificarse normalmente con el de oposición-organización»; en Las minorías en la estructura parlamentaria, Madrid, 1995, p. 45.

${ }^{6}$ Ver Minoría política y Tribunal Constitucional, Madrid 2002, pp. 147 y ss. 
como integrantes de una parte única que, por imperio de la Ley, ha de ser siempre plural» (STC 42/1985, de 15 de marzo, FJ 2).

Dado el carácter ad hoc de la agrupación de parlamentarios el TC ha venido exigiendo una declaración específica de los mismos para el recurso en cuestión, sin que baste una genérica. Para el TC «la legitimación para la acción de constitucionalidad... no puede ser delegada ni transmitido el poder para ejercerla y... en consecuencia, la decisión de impugnar no puede ser adoptada en términos genéricos, habilitando a delegados, apoderados o mandatarios para interponer o no la acción de inconstitucionalidad, según su propio criterio, contra las leyes que en el futuro se vayan promulgando» (STC 42/1985, de 15 de marzo, FJ 2).

En su momento razonó el Tribunal que «ni el poder general para pleitos ni la facultad genéricamente concedida para interponer ante el Tribunal Constitucional recursos de inconstitucionalidad «cualesquiera que fuesen sus clases» otorgan... una legitimación que, de acuerdo con la Constitución y la Ley, sólo surge de la concurrencia de voluntades, en número suficiente, de aquellos a quienes la Constitución ha otorgado esa facultad indelegable. No habiéndose probado en el presente caso, mediante la aportación del poder otorgado al efecto, como requiere el artículo 82.1 LOTC, la existencia de esa voluntad concurrente, es forzoso concluir que no existe tampoco parte legitimada para sostener la pretensión deducida en la demanda" (STC 42/1985, de 15 de marzo, FJ 3).

Con posterioridad, en la STC 150/1990, de 4 de octubre, FJ 1, se precisó esta doctrina afirmando que bastaba un poder general para pleitos otorgado al comisionado, siempre que se acompañe de un documento que acredite la voluntad de más de cincuenta Diputados de los otorgantes del poder de recurrir contra una Ley concreta, de modo que, siendo manifiesta la voluntad de recurrir de los Diputados que promueven la pretensión de inconstitucionalidad, y habiendo quedado explícita su voluntad de actuar representados por una determinada persona, no es necesaria la presentación de un poder especial.

En esta línea de flexibilización de los requisitos, y en una singular aplicación del principio pro actione, se encuentra también la STC 47/2005, de 3 de marzo, FJ 3, en la que se presumió que el otorgamiento de un poder general para pleitos días antes de la presentación del recurso contra la ley era un indicio serio de que «tales poderes se extendieron con el objeto de interponer el presente recurso de inconstitucionalidad contra la Ley Valenciana 2/1996, esto es, que existió la concurrencia de voluntades de más de 50 Diputados específicamente dirigida a la impugnación de una norma legal en el plazo de tres meses establecido por nuestra Ley Orgánica». 
Como vemos, ni grupos parlamentarios, contra lo que se defendió por algunos en el proceso constituyente ${ }^{7}$, ni partidos políticos son llamados a ejercer la acción de inconstitucionalidad. Se trata de agrupaciones ocasionales de Diputados y Senadores, que en número de cincuenta, o más, activan en un determinado momento el proceso, desligándose del mismo inmediatamente, pues éste deja de estar a su disposición, dado su carácter preferentemente objetivo.

Esta alternativa de no referir la legitimación a agrupaciones estables ha sido defendida por un sector de la doctrina ${ }^{8}$, y permite dotar al recurso de una gran flexibilidad, pues puede ser el resultado de la concurrencia de parlamentarios sometidos a diversas disciplinas, aunque tenga el inconveniente de que exige el acuerdo de un número significativo de voluntades, excluyendo a determinados grupos que no logren sobrepasar la barrera establecida. Es el problema de lo que se han llamado9 las minorías no protegidas.

Respecto al número de parlamentarios exigidos para la interposición del recurso de inconstitucionalidad los ordenamientos que hemos llamado a la comparación suelen ser bastante exigentes a la hora de establecer la barrera que es preciso superar y, en todo caso, la misma suele excluir a los grupos que se encuentran en franca minoría dentro de las Cámaras, reservando dicha facultad prácticamente para el principal partido de la oposición.

La decisión del constituyente podría revisarse, pero hay que tener en cuenta que ello supondría alterar claramente las bases del sistema, que ha tendido a reservar estos poderes a quienes formen una agrupación de cierta importancia entre los representantes del pueblo. En la práctica española, hasta ahora, los verdaderamente excluidos han sido grupos muy minoritarios en el ámbito nacional, y los nacionalistas se han apoyado en su dominio de los órganos autonómicos para llegar al TC.

Conviene cerrar este apartado, dedicado a la legitimación de las minorías parlamentarias, con una breve reflexión sobre la que en algunos países, singularmente Francia (art. 61 CF) y Portugal [art. 281.2 b) CRP], se reconoce a los Presidentes de las Cámaras. La norma francesa no es más que un reflejo de la importancia de estos órganos para la justicia constitucional de ese país, pues recuérdese, por ejemplo, que los Presidentes de la Asamblea Nacional y del Senado nombran cada uno de ellos un tercio de los miembros del Consejo Constitucional (art. $56 \mathrm{CF}$ ).

7 Enmienda del Grupo Parlamentario Vasco n. ${ }^{\circ}$ 684, que defendía la legitimación de «dos Grupos Parlamentarios» (CETP, p. 391). Fue retirada en la Comisión de Asuntos Constitucionales del Congreso de los Diputados.

${ }^{8}$ Principalmente D’Orazio, op. cit., pp. 78 y ss. 
El juego de estas facultades ha sido, sin embargo, escaso a partir de que se reconoció la legitimación a los parlamentarios. La falta de atribución de estos poderes a los Presidentes de las Cámaras españolas no parece criticable, desde el momento en que ello supondría simplemente dotar de los mismos a otros miembros de la mayoría, por lo menos en el color que hasta ahora han tenido, y en el hipotético supuesto de que no pertenecieran a la misma, y tal como demuestra el caso francés, su papel queda perfectamente cubierto por las agrupaciones de cincuenta Diputados o Senadores, sin que a los Presidentes se les pueda atribuir un rol político autónomo, que se explica en Francia por unas circunstancias muy concretas en la configuración de su sistema de control de constitucionalidad y de su régimen político.

d) Los órganos de las Comunidades Autónomas. Ámbito de la legitimación. Normas recurribles

Los datos normativos en España respecto a la legitimación de las Comunidades Autónomas en el recurso de inconstitucionalidad son a la vez sencillos y polémicos. Sencillos porque los mismos se derivan solamente de dos disposiciones: el tramo final del art. 162.1 a) CE que afirma que están legitimados para interponer el recurso de inconstitucionalidad «los órganos colegiados ejecutivos de las Comunidades Autónomas y, en su caso, las Asambleas de las mismas»; y el art. 32 LOTC que a la hora de precisar el alcance de dicha legitimación dispone en su apartado 2 que "para el ejercicio del recurso de inconstitucionalidad contra las Leyes, disposiciones o actos con fuerza de Ley del Estado que puedan afectar a su propio ámbito de autonomía, están también legitimados los órganos colegiados ejecutivos y las Asambleas de las Comunidades autónomas, previo acuerdo adoptado al efecto».

Polémicos porque las reglas impuestas por el art. 32.2 LOTC suponen dos limitaciones del objeto del posible recurso de inconstitucionalidad autonómico. Por un lado, las leyes del Estado recurribles son solamente las que puedan afectar a su propio ámbito de autonomía. Por otro, solamente pueden impugnarse las normas estatales y no las de otras Comunidades Autónomas o las de la propia. Como veremos, estas decisiones del legislador orgánico no han dejado de ser objeto de debate, pues no falta quien ha afirmado que no tienen «ninguna justificación ${ }^{10}$, y son merecedoras de algún comentario.

En primer término, por otro lado, conviene recordar que la jurisprudencia constitucional ha marginado de dicha legitimación a órganos de realidades que

\footnotetext{
9 Por Montilla en op. cit., pp. 110 y ss.

${ }^{10}$ M. L. Balaguer Callejón, El recurso de inconstitucionalidad, Madrid 2001, p. 82.
} 
no pueden consideradas como Comunidades Autónomas (Diputaciones Forales vascas, Ceuta y Melilla).

Reafirmado que sólo los órganos de las Comunidades Autónomas pueden acceder al recurso de inconstitucionalidad, procede ahora examinar cuáles de ellos tienen tal legitimación, y en ese sentido las normas son taxativas en el sentido de que se trata de los órganos colegiados ejecutivos y de las Asambleas de las mismas.

Respecto a los primeros llama inmediatamente la atención el que, contra lo que ha sido habitual en nuestro ordenamiento jurídico público, y sucede, como sabemos, en el nivel nacional, la lógica legitimación del ejecutivo autonómico no se ponga en manos del Presidente de la Comunidad sino en la del órgano colegiado que ostente dichas responsabilidades.

Se rechaza así lo que sería otra manifestación del principio de canciller y, aunque no cabe duda de que este tendría en su mano la resolución de los posibles conflictos mediante el cese de los que no atendieran a sus puntos de vista, tampoco la hay de que depositar la facultad de interponer el recurso en el órgano colegiado en su conjunto supone dar al problema una solución cualitativamente distinta.

El otro órgano autonómico que está legitimado para interponer recurso de inconstitucionalidad es la Asamblea legislativa. En el derecho extranjero que hemos traído a la comparación este dato no es frecuente, y solo en un particular procedimiento en Alemania se admite. Tampoco fue ésta la solución que prevaleció en determinados momentos de nuestro proceso constituyente en los que se prefirió atribuir dicha facultad al Presidente de dicha Asamblea, en una regulación que duró hasta el Dictamen de la Comisión Mixta Congreso-Senado, en el que, sin explicaciones, se sustituyó la facultad presidencial por la atribuida a la Asamblea en su conjunto.

La conclusión de todo este intento de profundizar en los rasgos de los órganos autonómicos legitimados para interponer el recurso de inconstitucionalidad bien pudiera ser que en España se ha alcanzado una regulación generosa del problema, que pone en manos de los principales actores políticos de cada Comunidad Autónoma - Gobierno y Parlamento - la posibilidad de presentar el recurso de modo que, en principio, la misma se presenta como muy abierta, como corresponde a un Estado fuertemente descentralizado en el que las nacionalidades y regiones se constituyen en protagonistas de muchos de los procesos de decisión, lo que aconseja dotarlas de estos poderes tan trascendentes respecto al control de constitucionalidad.

Conectado con este problema está el que se deriva del enunciado del art. 32.2 LOTC, que ya conocemos, en tanto en cuanto en el mismo, por un lado, parecen limitarse las leyes estatales susceptibles de ser impugnadas por estos órganos, y, por otro, no se permite el cuestionamiento de las normas de la propia 
Comunidad Autónoma y de otras. Ambas decisiones del legislador han hecho correr ríos de tinta, $\mathrm{y}$ han provocado numerosos pronunciamientos del Tribunal Constitucional. El primer problema con el que se enfrentó el TC fue el de cómo interpretar el texto del art. 32.2 LOTC que, introduciendo un matiz sobre el que no existía ningún guiño en la Constitución, afirmaba que los órganos autonómicos se entienden legitimados para ejercer el recurso de inconstitucionalidad contra normas, Leyes, o actos con fuerza de Ley del Estado «que puedan afectar a su propio ámbito de autonomía».

El largo recorrido que puede hacerse sobre la evolución de la jurisprudencia constitucional en la interpretación de dicho inciso del art. 32.2 LOTC, nos sirve para ilustrar claramente la idea de que lo que ha ido haciendo progresivamente el Tribunal, sin declararlo de una manera explícita, ha sido desactivar una restricción que había recibido muchas críticas y sobre cuya constitucionalidad algunos albergaban dudas fundadas.

Ha protagonizado, como dijeron algunos en su momento, «una verdadera mutación rectificando la interpretación auténtica del art. 162.1 a) realizada por el legislador en el art. 32.2 de la Ley Orgánica del Tribunal Constitucional. Si las Cortes Generales rectifican al constituyente el Tribunal Constitucional rectifica al legislador y enlaza con el primero" ${ }^{11}$.

No se da el paso, ciertamente arriesgado, de poner de manifiesto las dudas de inconstitucionalidad, pero el resultado final consiste en que, con los últimos pronunciamientos, resultaría muy difícil negar la legitimación a un órgano autonómico en prácticamente cualquier ley estatal.

El TC ha dejado evidentemente abierta esta posibilidad, reservándose así unas facultades que la LOTC claramente le atribuye, pero la administración que de las mismas ha hecho en los últimos tiempos da la impresión de que de lo que se trata es de reconocer que, ex. arts. 161.2 CE y 32.2 LOTC, los órganos autonómicos están legitimados para participar, mediante el recurso de inconstitucionalidad, en la depuración del ordenamiento en todos los ámbitos en los que exista una mínima conexión con las actividades de las Comunidades Autónomas, que, dado que estas se configuran cada vez más como Corporaciones dedicadas a proyectar sobre su territorio unas potestades públicas muy amplias, y que las mismas se vienen interpretando expansivamente, llegan a ser casi todos.

La otra restricción que el art. 32.2 LOTC impone a los órganos autonómicos, «concretando, acaso abusivamente» ${ }^{12}$, la legitimación genérica definida por

11 R. Canosa, op. cit., p. 85.

12 En opinión de M. A. García Martínez, El recurso de inconstitucionalidad, Madrid 1992, p. 157. 
el art. 162.1 a) CE, es la de que solamente podrán impugnar las leyes del Estado y no las de su Comunidad Autónoma y las de otras nacionalidades o regiones.

Como vemos el debate se centra en si es admisible la operación que ha realizado el art. 32 LOTC, consistente en, limitando el alcance del art. 162.1 a), restringir la legitimación de los órganos autonómicos a la impugnación de determinadas normas estatales. Las discusiones en el Tribunal con motivo de la STC 223/2006, de 6 de julio, fueron profundas, y el resultado final se alcanzó tras una serie de borradores contradictorios en los que no siempre se impuso la tesis reflejada en la misma, y ello porque la solución adoptada no puede dejar de ser polémica, puesto que intenta, a nuestro juicio infructuosamente, eludir el dato de partida de que la Constitución legitima a los órganos autonómicos para interponer el recurso de inconstitucionalidad, sin limitaciones de ningún tipo, que creemos que se deducen incorrectamente de supuestos principios constitucionales, o de la supuesta delegación a la LOTC (art. 165 CE) para matizar lo que no necesita matización.

La razón de ser de estas posturas podría ser la imitación de algunos modelos extranjeros o, simplemente, la convicción de que eran necesarios algunos límites a las capacidades de las Comunidades Autónomas. A estas alturas de nuestra evolución constitucional, del mismo modo en que se matizó, hasta prácticamente desactivarlo, como ya hemos visto, el inciso «que puedan afectar a su propio ámbito de autonomía"(art. 32.2 LOTC) parece necesario que la jurisprudencia constitucional convierta en doctrina del TC la del voto particular de la sentencia citada y, superando el curioso incidente parlamentario de la desaparición del art. 32.3 del proyecto de LOTC, reconozca que los órganos autonómicos pueden impugnar tanto las normas con rango de ley de sus Comunidades -para lo que, por supuesto habría que introducir en este ámbito, como ya hemos dicho, el recurso de las minorías- como las de otras.

\section{La cuestión de inconstitucionalidad}

La segunda manera de plantear dudas de inconstitucionalidad sobre normas con rango de ley ante el Tribunal Constitucional en España es, como sabemos, la cuestión de inconstitucionalidad ${ }^{13}$.

${ }^{13}$ Las páginas que siguen se apoyan, como se verá, en diversos trabajos sobre la cuestión de inconstitucionalidad en general, que han aparecido en los últimos años en España. Sin perjuicio de la referencias puntuales, debemos aquí manifestar nuestra deuda con los siguientes: M. del C. Blas- 
La norma básica reguladora de esta vía es el art. 163 CE que establece que "cuando un órgano judicial considere, en algún proceso, que una norma con rango de ley, aplicable al caso, de cuya validez dependa el fallo, pueda ser contraria a la Constitución, planteará la cuestión ante el Tribunal Constitucional en los supuestos, en la forma y con los efectos que establezca la ley, que en ningún caso serán suspensivos».

De este texto, y dada la perspectiva adoptada en nuestro trabajo, nos interesan, sobre todo, los dos primeros enunciados, es decir el que la cuestión pueda plantearla «un órgano judicial»y «en algún proceso», porque vamos a dedicarnos fundamentalmente a examinar su sentido tanto en las soluciones propuestas por la jurisprudencia constitucional, a veces muy polémicas, como en las reflexiones que las mismas han provocado y provocan en la mejor doctrina.

También es preciso decir algo respecto a la necesidad de estudiar estos problemas en el marco de un trabajo sobre la legitimación en los procesos constitucionales. Que ante un proceso constitucional estamos no creo que ofrezca la menor duda. Más problemático es que pueda hablarse en el mismo de legitimación, naturalmente del órgano judicial, para interponerlo, sobre todo si utilizamos aquel concepto de una manera rigurosa, que ya tuvimos ocasión de decir que no era la que iba a guiar nuestras incursiones en el tema que nos ocupa.

\section{1. Órgano judicial}

La primera conclusión a extraer sería, de este modo, la de que están legitimados todos los órganos del poder judicial, tal y como los enumera el art. 26 LOPJ atribuyéndoles «el ejercicio de la potestad jurisdiccional» —Juzgados de Paz; Juzgados de Primera Instancia e Instrucción, de lo Penal, de lo Contencioso-Administrativo, de lo Social, de Menores y de Vigilancia Penitenciaria; Audiencias Provinciales; Tribunales Superiores de Justicia; Audiencia Nacional; y Tribunal Supremo- y además los citados como órganos que ejercen jurisdicción fuera del poder judicial. Sobre otros entes acerca de los que existen dudas - árbitros, tribunales eclesiásticos, tribunales administrativos- habremos de decir algo en su momento.

co Soto La sentencia en la cuestión de inconstitucionalidad, Barcelona 1995; S. García Couso El juicio de relevancia en la cuestión de inconstitucionalidad, Madrid 1998; E. Corzo Sosa La cuestión de inconstitucionalidad, Madrid 1998; M. Fernández de Frutos El Procedimiento en la Cuestión de Inconstitucionalidad, Barcelona 2003; J. M. López Ulla La cuestión de inconstitucionalidad en el derecho español, Barcelona/Madrid 2000; A. Ribas Maura La cuestión de inconstitucionalidad, Madrid 1991; E. Marín Pageo La cuestión de inconstitucionalidad en el proceso civil, Madrid 1990; y P. Saavedra Gallo La duda de inconstitucionalidad, Córdoba 1986. 
En cuanto a los tribunales militares es un dato indiscutido por la doctrina, y por la jurisprudencia, el de que nos encontramos ante una verdadera jurisdicción especial, que ejerce la potestad jurisdiccional en el ámbito estrictamente castrense (art. 117.5 CE).

En el caso del Tribunal de Cuentas sí ha quedado reconocido que, como ha dicho el TC, «el enjuiciamiento contable que lleva a cabo el Tribunal de Cuentas constituye el ejercicio de una función jurisdiccional, plena y exclusiva, en un proceso especial por razón de la materia» (STC 215/2000, de 18 de septiembre, FJ 7).

En esa veste de órgano jurisdiccional parece que no puede dejar de reconocérsele la posibilidad de plantear cuestiones, aunque hay que decir que nos falta un pronunciamiento del Tribunal Constitucional al respecto, porque el de Cuentas no ha hecho uso de la misma hasta ahora.

Respecto a los tribunales consuetudinarios (Aguas de Valencia, Hombres Buenos de Murcia, etc.) no parece que pueda cerrarse completamente la posibilidad del planteamiento de la cuestión, si bien las peculiaridades del derecho que aplican la hacen difícil, como ocurre en el caso del tribunal del jurado, en el que, sin embargo, siempre está abierta dicha vía para el presidente del mismo, magistrado que es el que propiamente realiza una operación aplicativa de derecho, que puede conducirle a utilizar dichos mecanismos.

El carácter jurisdiccional de nuestro TC, que ahora prácticamente nadie niega y sobre el que no parece necesario extendernos ${ }^{14}$, es el punto de partida para considerar que la posibilidad del planteamiento de incidentes de inconstitucionalidad en los procesos constitucionales - que pudiera parecer paradójica, e incluso inadmisible, desde el momento en que choca con la regla de que el Tribunal Constitucional no actúa, en principio, de oficio- es una que no hay que descartar de ningún modo, entre otras cosas porque en la propia LOTC, y en algunos de sus procesos (recurso de amparo, conflicto positivo de competencia, conflicto en defensa de la autonomía local), prevé la misma.

Por otro lado, la posibilidad de que planteen cuestiones de constitucionalidad órganos realmente administrativos, pero denominados tribunales, y que actúan con procedimientos paraprocesales — por ejemplo Tribunales Económico Administrativos o Tribunal de Defensa de la Competencia - ha sido rechazada rotundamente por un sector de la doctrina ${ }^{15}$, y hay que tener en cuenta que las resoluciones de los mismos son normalmente impugnables ante la jurisdicción

${ }^{14}$ Una breve pero adecuada revisión del problema en Fernández de Frutos, op. cit., pp. 220222.

15 Ribas, op. cit., p. 43. 
contencioso-administrativa, momento en el que sí será posible solicitar el uso del mecanismo que estamos analizando. No parece muy discutible, sin embargo, que los mismos no encajan de ninguna manera en la denominación de «órgano judicial» prevista en el art. $163 \mathrm{CE}$.

Otra situación que provoca algunas disputas académicas es la de los tribunales eclesiásticos que en España es evidente que no forman parte del poder judicial, por lo que hay que considerarlos excluidos de la posibilidad de elevar cuestiones, siendo esta también la solución más habitual en el derecho comparado.

El problema que quizá es más polémico, sin embargo, es el del posible papel que pueden jugar los árbitros en el control de constitucionalidad. La cuestión dista mucho de ser pacífica en la doctrina, y en la jurisprudencia comparada, y tampoco lo es en nuestro país, en donde se han sostenido todo tipo de posturas.

Las diferentes posiciones pasan por adoptar una postura estricta o no respecto a lo que ha de entenderse por órgano judicial. Creemos que es más congruente con nuestro sistema jurisdiccional hacer lo primero, lo que llevaría a rechazar a los árbitros como órganos legitimados para interponer cuestiones, modo de ver las cosas que es, por cierto, el adoptado por el TC en algunas de sus resoluciones, como el ATC 259/1993, de 20 de julio, en donde se afirma (FJ 1) que «los "jueces árbitros" no pueden ser calificados como jueces en la acepción que a tal figura se adscribe en nuestra Ley suprema y en las demás del ramo", subrayando «la diferente configuración del "juez", titular de la potestad de juzgar y hacer ejecutar lo juzgado que emana del pueblo (art. $117 \mathrm{CE}$ ), revestido, por tanto, de imperium, y del "árbitro", desprovisto de tal carisma o cualidad, cuyo mandato tiene su origen en la voluntad de los interesados, dentro de una concreta contienda o controversia», de lo que se deduce que "el árbitro... no nos puede plantear una cuestión de inconstitucionalidad por estar reservada a los órganos judiciales».

\subsection{En un proceso}

Dilucidado lo que creemos que debe entenderse por «órgano judicial», cabe recordar que el art. $163 \mathrm{CE}$ exige que concurra otro requisito, que podría denominarse objetivo, para que pueda plantearse la cuestión, y que es que la duda de constitucionalidad le surja a aquél «en algún proceso».

Este enunciado tan sencillo no ha dejado de provocar serias discusiones en el seno del TC, como veremos, pues ha sido utilizado para cerrar el paso a determinadas cuestiones que no han sido admitidas, en una actitud, no precisamen- 
te unánime, de exigir el cumplimiento estricto de los mandatos constitucionales, que contrasta con la flexibilidad de la que ha hecho gala el Tribunal Constitucional en otras ocasiones.

Centrándonos en el tema de este trabajo, lo que se ha producido con el ATC 505/2005, de 23 de diciembre, es una revisión en sentido restrictivo de una jurisprudencia que iba en la línea de, con la exclusión de las actividades propiamente gubernativas, considerar que el elemento subjetivo de la cuestión, la presencia de un juez o tribunal, prevalecía sobre uno objetivo que tendía a difuminarse. Con el Auto que comentamos se reconstruye esa tendencia en un caso concreto especialmente conflictivo. Habrá que estar atentos en el futuro a nuevos desarrollos que debieran contribuir a perfilar aún más lo que debemos entender por «actividad jurisdiccional» en la que se ejercen "poderes decisorios». No es criticable que esto se vaya haciendo caso por caso, porque la jurisprudencia constitucional no tiene por qué dedicarse a elaborar construcciones doctrinales, tarea esta de otros operadores jurídicos, pero si es deseable que se vaya elaborando una línea jurisdiccional que permita a jueces y tribunales saber a qué atenerse cuando pretendan presentar una cuestión de inconstitucionalidad.

En nuestra manera de ver las cosas, avalada por las experiencias extranjeras, y por la reflexión de que el objetivo principal de las cuestiones es la depuración del ordenamiento, hubiera sido deseable una flexibilización de los requisitos que hubiese permitido la admisión a trámite de la planteada por la Juez de Denia. Es cierto que para ello hacía falta forzar de alguna manera la letra de las leyes en presencia, pero, a nuestro juicio, el sistema no hubiera sufrido en exceso si se hubiera adoptado esta actitud, que lo que es indudable es que hubiese llevado ante el Pleno del Tribunal un problema de fondo que no ha dejado de plantearse a través de un recurso de inconstitucionalidad, pero que no había, en mi modesta opinión, que dejar de examinar, desde el momento en que lo traía ante el TC un juez al que le surgían en un expediente dudas sobre la constitucionalidad de una norma.

\subsection{Las partes litigantes en el proceso $a$ quo y la cuestión de inconstitucionalidad}

Todos los materiales doctrinales y jurisprudenciales nos conducen a la conclusión de que, en nuestro ordenamiento, la posición de las partes en el proceso a quo, con respecto a la posibilidad del planteamiento de cuestiones de inconstitucionalidad, es la de unos simples promotores, que ven como sus intenciones en este campo no bastan en absoluto para que se de dicho planteamiento, reservado a los órganos judiciales. Los datos normativos y de otro tipo son 
tajantes. Lo más que puede hacer quien participa en un proceso, y considera que una norma que se va aplicar en el mismo es inconstitucional, es instar al juez a ponerse en marcha, pero no puede decirse que posea ningún tipo de acción para su defensa frente a las leyes contrarias a la norma suprema. La misma está reservada al juez, en un sistema como el nuestro en que, como ya hemos dicho repetidas veces, la legitimación en los procesos de inconstitucionalidad no se ha abierto a los ciudadanos en general, ni siquiera cuando tienen la condición de partes en un proceso.

\section{El control previo de constitucionalidad de los tratados}

En este proceso constitucional es la exclusión de las minorías el dato que nos parece menos de recibo. No se nos oculta que hay quien la ha justificado afirmando que «contra lo que sucede en el recurso de inconstitucionalidad, en la medida en que el control previo no responde a la lógica de proteger minoría frente a mayoría, no tiene sentido otorgar legitimación para instar el control previo a aquélla ${ }^{16}$, pero no podemos sino mostrarnos en desacuerdo con esta manera de ver las cosas que considera al control previo de tratados como un instrumento con una ratio absolutamente diferente de la del control de constitucionalidad de las leyes que llevaría a aplicarle unos presupuestos diferentes.

No vamos a negar las diferencias que existen, pero no creemos que en las mismas se pueda basar la exclusión de las minorías, que pueden contribuir de una manera trascendente a la depuración preventiva del ordenamiento que está en la base de este proceso constitucional. El ejemplo francés avala nuestra postura, y demuestra que un número significativo de parlamentarios, que debiera ser de cincuenta Diputados o cincuenta Senadores, como exige la coherencia del sistema, pueden contribuir decisivamente, con el planteamiento ante el Tribunal Constitucional de sus dudas sobre la conformidad de un determinado tratado con la Constitución, a que no se llegue a la indeseable situación en la que el control a posteriori demuestre la inconstitucionalidad de dicha norma.

La cicatería de la CE y de la LOTC en este terreno ha provocado, entre otras cosas, que la utilización de este mecanismo haya sido escasa, y lastrada por el hecho de que se ha usado exclusivamente para beneficiar los intereses de la mayoría, si bien debe reconocerse que esto ha sido más patente en el caso de la segunda Declaración solicitada al TC.

16 P. Pérez Tremps en "Comentario al art. 78», en J. L. Requejo (coord.) Comentarios a la LOTC, Madrid 200, p. 1255. 
No se entiende por qué no pueden los parlamentarios que lleguen al número mágico de cincuenta, que ya sabemos que supone un mínimo de seriedad, y peso específico en el sistema constitucional, plantear sus dudas al Tribunal Constitucional, y no se nos diga que no hay aquí problemas de protección de minorías, porque, aparte de que los mismos puede existir, la legitimación de aquellos ha quedado demostrado ya hasta la saciedad que no tiene que ver solamente con estos sino con la atribución, a un sector importante de la vida política de un país, de la posibilidad de cuestionar decisiones de especial trascendencia desde la perspectiva de su constitucionalidad, ante el árbitro designado para resolver estos problemas.

Cerrar este camino no tiene sentido, y la explicación más probable de que lo hiciera la CE es que se fijó como modelo en el texto de la CF de 1958 antes de la reforma de 1992. Si los franceses han corregido dicha situación, nada nos impide tomarlos de nuevo como modelo, aunque para ello haya que recorrer el siempre complicado camino de la reforma constitucional, recogiendo así en un nuevo art. 95.2 CE al menos la legitimación de los parlamentarios. El sistema saldría ganando indudablemente con esta reforma y el mecanismo que estamos examinando podría recibir un nuevo impulso que lo hiciera mucho más funcional que hasta ahora.

\section{EL TRIBUNAL COMO TRIBUNAL DE CONFLICTOS}

\section{Los conflictos de competencia}

\subsection{Positivos. El dominio de los ejecutivos}

La legitimación para interponer el conflicto positivo se atribuye a los gobiernos del Estado y de las Comunidades Autónomas, en una manera de resolver el problema que cuenta con el apoyo de las experiencias extranjeras en estas materias.

El diseño de la LOTC tiene en su base el reconocimiento a muy pocos sujetos de la facultad de plantear el conflicto. Solamente los vértices de los aparatos ejecutivos del Gobierno y las Comunidades Autónomas. Se trata, como ha escrito García Roca, de una "legitimación tasada o de enumeración cerrada» ${ }^{17}$ que excluye a todo otro tipo de actores, por más que en determinadas normas se haya intentado ampliar el círculo de los legitimados.

${ }^{17}$ J. García Roca, Los conflictos de competencia entre el Estado y las Comunidades Autónomas, Madrid 1993, p. 44 
Esa reconducción a los gobiernos es lógica dentro de la habitual configuración de los poderes públicos en las sociedades modernas. No cabe duda de que puede plantear algunas disfunciones, en tanto en cuanto aquéllos, en determinados casos, pudieran no representar correctamente los intereses de los entes a los que sirven, pero tampoco cabe duda de que la simplificación que supone el sistema adoptado soluciona más problemas de los que plantea, por lo que tampoco puede criticarse más allá de señalar posibles perplejidades.

No está de más, finalmente, que subrayemos que, en línea con las experiencias extranjeras comentadas, el Tribunal Constitucional debe exigir, para el planteamiento de este tipo de conflictos, certificación del acuerdo del órgano colegiado ejecutivo correspondiente, en atención a la importancia del mecanismo en sí y a la necesidad de que la utilización del mismo se reserve a problemas de especial importancia sobre los que deberá pronunciarse el ente vértice del ejecutivo del Estado o de las Comunidades Autónomas.

\subsection{Negativos. Particulares y Gobierno en el proceso conflictual}

Vemos aquí como el problema del respeto del orden constitucional de competencias se abre a la intervención de los particulares, si bien de esta manera indirecta de provocar un conflicto entre dos administraciones renuentes a actuar.

El resultado práctico de la regulación refleja el hecho indudable de que "difícilmente quienes están legitimados para promoverlos tendrán interés en hacerlo» ${ }^{18}$, con lo que nos hallamos ante un procedimiento casi virgen, en el que nunca se ha alcanzado una Sentencia sobre el fondo del asunto, y que es de una utilidad dudosa, aunque puede considerárselo como un mecanismo de cierre del sistema de conflictos en el que, insistimos, los ciudadanos aparecen como los posibles instigadores de su puesta en marcha, independientemente de que sus principales sujetos sean, de manera evidente, Estado y Comunidades Autónomas. Esta última característica dota a estos conflictos negativos de una interesante singularidad desde la perspectiva que hemos adoptado en este trabajo.

Respecto a los conflictos negativos promovidos por el Gobierno (art. 71 y ss.) nos hallamos aquí ante un proceso ciertamente singular, de nula aplicación práctica, pero que pudiera resultar interesante como instrumento de control de la actividad - más bien de la falta de actividad- de las Comunidades Autónomas por parte del Estado.

${ }^{18}$ Germán Fernández Farreres: «Comentario al art. 68», en J. L Requejo (coord) Comentarios,,,,, op. cit., p. 1106. 
La asimetría es patente puesto que el conflicto solo puede plantearlo el Gobierno de la Nación, lo que ha llevado a algunos a sostener que lo que se persigue aquí «más que el mantenimiento del orden constitucional de distribución de competencias y la garantía de las competencias propias... es la defensa del interés general... consistente en que las Comunidades Autónomas en que se articula territorialmente el Estado en su conjunto asuman y ejerzan efectivamente las competencias que les han sido atribuidas» ${ }^{19}$.

En todo caso dicha situación, que cierra completamente a las Comunidades Autónomas la posibilidad de entablar un conflicto negativo, no resulta de recibo en un Estado compuesto en el que aquéllas pueden también ejercer funciones de defensa del interés general, que no hay que considerar como exclusivas de los órganos centrales del mismo.

\section{Impugnaciones del art. 161.2 CE}

Este mecanismo ${ }^{20}$ ha sido considerado como un instrumento del Estado central para controlar, con el privilegio de la suspensión automática, que no tiene en exclusiva, pues también puede ser invocado en el recurso de inconstitucionalidad y en el conflicto positivo de competencias (arts. 62 y 64.2 LOTC), la producción normativa de las Comunidades Autónomas. Por lo que a nosotros interesa cabe destacar que se encuentra, como hemos podido ver, en manos del Gobierno de la Nación.

En este estrecho marco — de «excepcionalidad» ha hablado E. Lucas ${ }^{21}$ - es en el que se desarrollan los problemas de legitimación, que no son tales, pues las normas que ya hemos visto son tajantes en el sentido de poner estos poderes en manos del Gobierno de la Nación, entendido como garante, en última instancia, de la constitucionalidad de los actos de las Comunidades Autónomas, que controla a través de estos poderes impugnatorios.

19 G. Fernández Farreres, «Comentario al art. 71»; en J. L. Requejo (coord.) Comentarios..., op. cit., p. 1122.

${ }^{20}$ El trabajo más completo en esta materia, que revisa todas las implicaciones del art. 161.2 CE no sólo en el proceso que nos ocupa sino también en el recurso de inconstitucionalidad y en el conflicto de competencias, es el de E. Lucas Murillo de la Cueva La impugnación de las disposiciones y resoluciones autonómicas ante el Tribunal Constitucional. Estudio del art. 161.2 de la Constitución, Oñati, 2005, al que cabe remitir en su totalidad. También debe consultarse P. J. Tenorio Sánchez, «Impugnación por el Gobierno de disposiciones y actos de las Comunidades Autónomas por motivos de inconstitucionalidad no competenciales», Revista de Derecho Político UNED n. ${ }^{\circ} 60$ (2004), pp. 99 y ss.

${ }^{21}$ Op. cit., p. 230. 
Es dicho Gobierno el legitimado activamente, mientras que la legitimación pasiva corresponde a los órganos de las Comunidades Autónomas responsables de las disposiciones o resoluciones impugnadas. Este planteamiento es consecuencia del carácter «unidireccional $»^{22}$ de este proceso, y viene impuesto por la propia Constitución, como ya sabemos, de modo que puede coincidirse con Tenorio en que la legitimación activa corresponde «exclusivamente» a aquél por imperativo del art. 161.2 CE, «sin que quepa ampliar el círculo de sujetos legitimados con base en el art. 162.2 $\mathrm{CE} »^{23}$.

\section{El conflicto en defensa de la autonomía local}

Abierta la caja de los truenos de la posibilidad de impugnar leyes por parte de órganos municipales, inmediatamente el legislador se dio cuenta de que un reconocimiento demasiado generoso de la legitimación de entes locales para interponer este tipo de conflictos podría poner en peligro los delicados equilibrios en los que se basa la justicia constitucional en nuestro país, y en todos los que conocen tal sistema. Llegó así el momento de los recortes y las limitaciones, recortes y limitaciones que han llevado a los comentaristas a hablar de uno de los "puntos probablemente más cuestionables y polémicos del nuevo proceso $»^{24}$, del «alcance notablemente restrictivo» ${ }^{25}$ de las soluciones adoptadas, y de que se pone este instrumento solamente en manos de los partidos mayoritarios ${ }^{26}$. Para algunos autores «si de verdad se quería facilitar un cauce efectivo de defensa, debían haberse flexibilizado algo más las exigencias de la legitimación ${ }^{27}$

La gran justificación para esta actitud del legislador es la situación del TC en lo que respecta a su carga de trabajo, que hacía necesario recortar la legitimación "con factores, si no disuasorios del abuso de la acción, al menos garantes de que las demandas tuvieran una racionalidad en su planteamiento» ${ }^{28}$.

${ }^{22}$ La expresión es de E. Lucas en op. cit., p. 239.

23 Op. cit., p. 119.

${ }_{24}$ Porras Ramírez, J. M., El conflicto en defensa de la autonomía local ante el Tribunal Constitucional, Madrid 2001, pp. 75-76.

${ }^{25}$ Op. ult. cit., p. 77. De evidente carácter restrictivo habla también Fernández Farreres en $E l$ conflicto de defensa de la autonomia local: justificación, configuración jurídica y funcionalidad; Anuario de Gobierno Local 2001, p. 62.

${ }^{26}$ Como señala de nuevo Porras en op. cit., p. 81.

27 Fernández Farreres, op. cit., p. 63.

28 Cabello Fernández, El conflicto en defensa de la autonomía local, Madrid 2003, p. 160. 
Las primeras limitaciones tienen que ver con la decisión de contraer la legitimación a los entes locales a los que la $\mathrm{CE}$ reconoce la autonomía para la gestión de sus intereses, lo que conduce a no otorgarla a aquellos que no tienen tal reconocimiento, como, llamativamente las comarcas y las diversas asociaciones de municipios.

Inmediatamente el art. 75 ter LOTC realiza una enumeración, que completan las disposiciones adicionales tercera y cuarta de la misma ley, en la que vamos viendo como, en primer lugar, aparecen como legitimados [apartado a)] «el municipio o provincia que sea destinatario único de la ley», debiendo entenderse, siguiendo a Naranjo, como ley de destinatario único a «aquélla cuyo ámbito personal de aplicación viene constituido por un solo sujeto o ente territorial $»^{29}$.

El segundo grupo de legitimados [art. 75 ter b)] es el de «un número de municipios que supongan al menos un séptimo de los existentes en el ámbito territorial de aplicación de la disposición con rango de ley, y representen como mínimo un sexto de la población oficial del ámbito territorial correspondiente».

En línea con esta tendencia a dotar de apoyos a los litigantes está el apartado c) del art. 75 ter 1, que reconoce la legitimación para recurrir a «un número de provincias que supongan al menos la mitad de las existentes en el ámbito territorial de aplicación de la disposición con rango de ley, y representen como mínimo la mitad de la población oficial».

Estos dos grandes bloques previstos en el art. 75 ter LOTC se complementan, como ya sabemos, con las previsiones de las disposiciones adicionales tercera y cuarta de la misma ley. En la primera se establece (apartado 1) que las referencias a las provincias contenidas en la LOTC se entenderán realizadas a las islas en las Comunidades Autónomas de las Illes Balears y Canarias, y que (apartado 2) además de los sujetos que ya sabemos legitimados lo estarán también, frente a leyes y disposiciones normativas con rango de Ley de la Comunidad Autónoma de Canarias, tres Cabildos, y de la Comunidad Autónoma de las Illes Balears, dos Consejos Insulares, aun cuando en ambos casos no se alcance el porcentaje de población exigido en el art. 75 ter. 1.

En la disposición adicional cuarta en primer lugar se establece (apartado 1) que los conflictos de competencia que se puedan suscitar entre las instituciones de la Comunidad Autónoma del País Vasco y las de cada uno de sus Territorios Históricos se regirán por lo dispuesto en el art. 39 de su Estatuto de Autono-

${ }^{29}$ El proceso constitucional para la protección de la autonomía local en España y Alemania, Madrid 2003, p. 53. 
mía ${ }^{30}$ y que (apartado 2) en el ámbito de la Comunidad Autónoma del País Vasco, además de los sujetos legitimados a que se refiere el artículo 75 ter.1, lo estarán también, a los efectos de los conflictos en defensa de la autonomía local, las correspondientes Juntas Generales y las Diputaciones Forales de cada Territorio Histórico, cuando el ámbito de aplicación de la ley afecte directamente a dicha Comunidad Autónoma.

Para finalizar con este apartado cabe hacer referencia a las reglas de los apartados 2 y 3 del art. 75 ter, que exigen el acuerdo del órgano plenario de las Corporaciones locales con el voto favorable de la mayoría absoluta del número legal de miembros de las mismas, un requisito que para algunos refuerza las dificultades para que el conflicto pueda materializarse ${ }^{31}$, y la solicitud de dictamen del Consejo de Estado u órgano consultivo correspondiente de manera previa a la formalización del conflicto. En el apartado 4 se prevé que las asociaciones de entidades locales, que ya sabemos que no están legitimadas, podrán asistir a los entes locales a fin de facilitarles el cumplimiento de los requisitos establecidos.

\section{Los conflictos entre órganos constitucionales}

Frente a regulaciones extranjeras extremadamente generosas en estas materias, sobre todo en la interpretación de fórmulas constitucionales deliberadamente abiertas, la española es de una cicatería que podría calificarse de sorprendente, si no fuera porque quizás pudiera plantearse que dichas experiencias foráneas no son precisamente un ejemplo a seguir.

En España nos encontramos con una enumeración cerrada que limita los conflictos entre órganos constitucionales a los que puedan oponer «al Gobierno con el Congreso de los Diputados, el Senado o el Consejo General del Poder Judicial; o a cualquiera de estos órganos constitucionales entre sí» [art. $59.1 \mathrm{c}$ ) LOTC, que como se sabe, amplía las competencias del TC de acuerdo con lo previsto en el art. $161.1 \mathrm{~d}) \mathrm{CE}]$.

30 «Los conflictos de competencia que se puedan suscitar entre las instituciones de la Comunidad Autónoma y las de cada uno de sus Territorios Históricos se someterán a la decisión de una comisión arbitral, formada por un número igual de representantes designados libremente por el Gobierno Vasco y por la Diputación Foral del Territorio interesado y presidida por el Presidente del Tribunal Superior de Justicia del País Vasco, conforme al procedimiento que una ley del Parlamento Vasco determine».

${ }^{31}$ Fernández Farreres, en op. cit., p. 63. 


\subsection{Los incluidos y sus partes. Algunas perplejidades}

No hace falta que volvamos a repetir que las Cámaras legislativas nacionales, el Gobierno y el Consejo General del Poder Judicial son los órganos en principio legitimados en este conflicto.

Respecto a Congreso y Senado no parece que existan muchas dudas en cuanto a su condición de órganos constitucionales que en determinados momentos pueden verse en la necesidad de defender sus potestades y, de hecho, los dos conflictos planteados, y resueltos mediante las SSTC 45/1986, de 17 de abril, y 234/2000, de 3 de octubre ${ }^{32}$, lo fueron a instancias del Consejo General del Poder Judicial y el Gobierno frente a la Cámaras, lo que demuestra que la actividad de las mismas puede ser, si no muy frecuente, sí, al menos, ocasional fuente de problemas. Esto hace que su legitimación sea indiscutible no solo porque las mencione la LOTC.

Las controversias pueden nacer, sin embargo, de dos facetas de las Asambleas legislativas que en la Ley no se han tenido en cuenta. En primer lugar, la de que en nuestro sistema constitucional existe otra Cámara, que es la suma de Congreso y Senado, las llamadas Cortes Generales en sesión conjunta.

En segundo, la de que ha sido tradicional en los sistemas que estamos usando a fines comparativos el reconocimiento de determinadas capacidades de impugnar tanto a algunos órganos de las Cámaras como a las llamadas «fracciones de órgano» en la terminología alemana, vía por la que se acabaría legitimando a las minorías e incluso al parlamentario individual.

Por lo que se refiere a la legitimación del órgano constitucional Gobierno, no dejan de aparecer algunas curiosidades sobre las que conviene detenerse, siquiera sea brevemente.

En primer lugar, resulta llamativo que en un régimen «cancilleresco"(Rubio) como el nuestro -en el que la posición del Presidente del Gobierno se encuentra tan notablemente reforzada, por comparación a la que es habitual en otros regímenes parlamentarios de nuestro entorno, quizás con la única excepción del Reino Unido, que hasta sería posible la recepción de la sin duda exagerada categoría de la «dictadura electiva», manejada en este último país por Lord Hailsham, para describir nuestro sistema institucional- la legitimación para plantear el conflicto por parte del Ejecutivo no se atribuya al Presidente del Gobierno,

32 Sobre este segundo conflicto, permítasenos remitir a nuestro trabajo I. Torres Muro «¿Subordinando al Senado? La declaración gubernamental de urgencia, ex art. $90.3 \mathrm{CE}$, ante el Tribunal Constitucional (STC 234/2000)", en Repertorio Aranzadi del Tribunal Constitucional, n. ${ }^{\circ}$ 21-22; Febrero 2001; pp. 15 y ss. 
como sucede en el recurso de inconstitucionalidad, sino al Gobierno en su conjunto, lo que viene a indicar que dicha facultad no se reserva al «Canciller» ${ }^{33}$ sino que este debe lograr el acuerdo para ejercerla de sus compañeros de Ejecutivo.

Por lo que respecta a la legitimación del Consejo General del Poder Judicial $^{34}$, no parecen derivarse excesivos problemas del hecho de atribuir al Pleno de dicho Consejo la facultad de interponer el conflicto, facultad que ha sido utilizada históricamente por el mismo en los conflictos que dieron origen a la STC 45/1986, de 17 de abril en los que (véanse los Antecedentes de dicha Sentencia) el Presidente de dicho órgano planteaba «de conformidad con lo acordado por su Pleno» conflicto entre órganos constitucionales del Estado.

En este caso la norma contenida en el art. 73.1 LOTC — «por acuerdo de sus respectivos Plenos»- no provoca más perplejidades que las que pudieran proceder de la hipotética necesidad de reconocer, de lege ferenda, facultades de interposición del conflicto a una minoría significativa del órgano, dada la dinámica mayorías-minorías políticas en la que el mismo parece haber entrado en los últimos años.

La opción de la LOTC es, por tanto, restrictiva, una vez más, pero aquí sí creemos que existen buenas razones para mostrarse prudentes en el reconocimiento de estas facultades. La primera, la existencia de tradicionales, eficaces, y consolidados, mecanismos al margen del TC para resolver los posibles conflictos de atribuciones entre la jurisdicción ordinaria y otros poderes del Estado, como los que están previstos en la Ley orgánica 2/1987, de 18 de mayo, de conflictos jurisdiccionales. La segunda, que debe resistirse a toda costa la posible tendencia a abrir demasiado la legitimación en estas materias que pudiera poner en peligro, dado el exceso de procesos planteados, los delicados equilibrios propios de la jurisdicción constitucional, que tiene que, en principio, reservarse, para litigios verdaderamente importantes, que enfrenten, en el proceso que ahora estamos examinando a verdaderos «órganos constitucionales», si es posible extraer algún significado preciso de este equívoco término, reivindicando verdaderas competencias constitucionales y no poderes que tienen otras vías para defender adecuadamente. Procede resistirse en la medida de lo posible, y para ello hay buena

${ }^{33}$ No evidentemente en el sentido habitual en toda Hispanoamérica de Ministro de Asuntos Exteriores, sino en el germánico de «Kanzler» o primer ministro.

34 Sobre el mismo, en general, se sigue leyendo con aprovechamiento M. Terol, El Consejo General del Poder Judicial, Madrid 1990, y, y desde luego, los diversos trabajos de M. Gerpe. El último que conocemos «La configuración constitucional del Consejo General del Poder Judicial» en VV.AA. La democracia constitucional. Estudios en homenaje al Profesor Francisco Rubio Llorente, Madrid 2002, pp. 985 y ss. 
base en la LOTC, a lo que se ha llamado «atomización» ${ }^{35}$ o, más gráficamente aún, "pulverización» ${ }^{36}$ " deshilachamiento» ${ }^{37}$ de los legitimados, que han llegado a calificarse, con cierta dosis de ironía, de «micropoderes» ${ }^{38}$.

\subsection{Los excluidos coherentemente}

El debate sobre los sujetos legitimados para interponer el conflicto entre órganos constitucionales no se ha referido solamente a los aspectos que acabamos de examinar sobre aquellos que menciona el art. $59.1 \mathrm{c}$ ) LOTC, sino que también ha tenido como objeto las que podrían llamarse exclusiones coherentes, es decir la falta de legitimación del algunos órganos que, a veces, un sector de la doctrina ha considerado como incorrecta, pero que, a nuestro juicio, puede defenderse en todos los casos.

El primer órgano excluido es el Jefe del Estado; es decir, en nuestro país, el titular de la Corona, Reina o Rey, dependiendo del cumplimiento de las previsiones sucesorias. Su posición super partes aconseja claramente que no participe en este tipo de conflictos.

Lo mismo sucede con el Tribunal Constitucional, y no solamente por aplicar el viejo adagio «iudex in causa propria quis esse non potest» (nadie puede ser juez en causa propia) ${ }^{39}$, dado que el TC se encontraría eventualmente decidiendo en un conflicto en el que él es parte, sino también porque de acuerdo con la LOTC el mismo, intérprete supremo de la Constitución, es independiente de los demás órganos constitucionales y está sometido sólo a aquella y a la LOTC (art. 1.1 de ésta). Además, (art. 4 LOTC) en ningún caso se le podrá promover cuestión de jurisdicción o competencia y deberá ser él el que apreciará, de oficio o a instancia de parte, su falta de jurisdicción o de competencia.

35 P. Tenorio, «Los conflictos de atribuciones entre poderes del Estado en Italia: algunos aspectos", Revista de la Facultad de Derecho de la Universidad Complutense, n. ${ }^{\circ} 73$ (1988), p. 385.

${ }^{36}$ R. Bin, «L' ultima fortezza. Teoria della Costituzione e conflitti di attribuzione», Milan 1996, p. 15. Un ejemplo de como en un período determinado se ha interpretado en Italia ampliamente el concepto de "potere» legitimado para la interposición del conflicto de atribuciones en R. Romboli (a cura di) Aggiornamenti in tema di processo costituzionale (1993-1995), Turín, 1996, pp. 337 y ss.

37 E. Malfatti y otros, Giustizia Costituzionale, Turín 2003, p. 230.

38 Por Sorrentino en Pizzorusso y otros, Garanzie Costituzionali, Bolonia/Roma, 1981, pág. 448.

39 Hay otras versiones del mismo, como la de Ne quis in su causa dicet, vel ius sibi dicat; la de Nemo sibi sit iudex, y la de Iudex in propria causa nequit cognoscere. Sobre todas ellas, R. Domingo (dir) Principios de Derecho global. Aforismos juridicos comentados, Cizur Menor, 2003, p. 154. 
Se ha apuntado, por ciertos autores, que resulta ilógica la exclusión del Defensor del Pueblo, alto comisionado de las Cortes Generales, designado por éstas para la defensa de los derechos constitucionales, a cuyo efecto podrá supervisar la actividad de la Administración, dando cuenta a las Cortes Generales (art. $54 \mathrm{CE})$.

En el esquema de la LOTC dicho estado de cosas resulta coherente, desde el momento en que, en primer lugar, mal podría el alto comisionado enfrentarse a Congreso y Senado, independientemente de que pudiera informar a los mismos de disfunciones en la Administración parlamentaria, y algo parecido ocurre con el CGPJ, cuyas competencias constitucionales difícilmente chocan con las del Defensor del Pueblo. Por lo que toca al Gobierno las atribuciones de nuestro Ombudsman se refieren fundamentalmente a la Administración más que al órgano constitucional Gobierno, que, sin embargo, es la cabeza de aquélla.

Algo similar ocurre con el Consejo de Estado, supremo órgano consultivo del Gobierno (art. 107 CE; art. 1.1 LOCE), en cuyo caso, si se quiere, este carácter de mero órgano auxiliar, o de relevancia constitucional, es aún más claro, y reafirmado por la jurisprudencia (Por todas, STC 56/1990, de 29 de marzo, FJ 37), sin dejar de tener importancia el hecho de que dada su condición de institución fundamentalmente consultiva, que se refleja en su Ley orgánica, difícilmente puede entrar en conflicto con otras.

\subsection{El curioso caso del Tribunal de Cuentas}

No podemos cerrar este apartado sin hacer una referencia a la curiosa situación del Tribunal de Cuentas ${ }^{40}$, excluido en los debates de la LOTC del círculo de privilegiados al que nos hemos referido, con el argumento de que la institución no culminaba un poder del Estado, y que ha vuelto a plantear su legitimación con el art. 8 de la LOTcu ( 1 . Los conflictos que se susciten sobre las competencias o atribuciones del Tribunal de Cuentas serán resueltos por el Tribunal Constitucional»), poniendo de nuevo sobre la mesa una situación histórica muy concreta, como la que le llevó a estar legitimado en la Constitución de la II República (art. 120.3).

A falta pues de unas orientaciones claras en la doctrina, en la jurisprudencia y en las experiencias extranjeras, parece posible, sin embargo, reconducir el

40 Ver, en principio, García Roca, El conflicto entre órganos constitucionales, Madrid 1987. pp. 68 y 69; Gómez Montoro, El conflicto entre órganos constitucionales, Madrid 1992, pp. 352 y ss; y Trujillo, Los conflictos entre órganos constitucionales del Estado, Madrid 1995, pp. 282 y ss. 
problema, como ha hecho, por ejemplo, Gómez Montoro ${ }^{41}$, resaltando que el TC ha mostrado una resistencia implícita, cuando no ha convocado al Tribunal de Cuentas a participar en los pocos conflictos entre órganos constitucionales que se ha producido hasta ahora, y a los que ya hicimos alguna referencia, a admitir la legitimación del Tribunal de Cuentas, que probablemente sería explícita si éste llegara a plantear una pretensión de este tipo.

Hasta ahora todo son especulaciones de laboratorio, entre otras cosas porque la legislación en la materia - leyes sobre el Tribunal de Cuentas; ley de conflictos jurisdiccionales - ha limitado las posibilidades de que este órgano necesite acudir a la legitimación del art. 8 de su Ley orgánica. No cabe descartar que está situación pueda darse, pero, por ahora, los razonamientos más fundados van en el sentido de que esta norma supone un callejón sin salida que habrá que resolver en su momento declarando su práctica inanidad.

\section{EL TRIBUNAL COMO JUEZ DE LOS DERECHOS FUNDAMENTALES. LA LEGITIMACIÓN EN EL RECURSO DE AMPARO}

\section{Las reglas en presencia}

Los primeros problemas respecto a la legitimación en el recurso de amparo se derivan de la existencia de normas aparentemente contradictorias, como las que se contienen en al art. 162.1. b) CE, en el que se establece que está legitimada «para interponer el recurso de amparo, toda persona natural o jurídica que invoque un interés legítimo, así como el Defensor de Pueblo y el Ministerio Fiscal», y en el art. 46.1 LOTC, que prevé que "están legitimados para interponer el recurso de amparo constitucional: a) En los casos de los artículos 42 y 45, la persona directamente afectada, el Defensor del Pueblo y el Ministerio Fiscal; b) En los casos de los artículos 43 y 44, quienes hayan sido parte en el proceso judicial correspondiente, el Defensor del Pueblo y el Ministerio Fiscal».

La mejor doctrina ha salvado esa aparente contradicción subrayando que la regla básica de legitimación es la contenida en el texto constitucional, que ha sido matizada por la LOTC y por la doctrina del TC en el sentido de que, por un lado, la exigencia de agotar la vía judicial previa para interponer el recurso de amparo no es una exigencia absoluta y, por otro, el cumplimiento de la exigencia de haber sido parte en la vía judicial previa es conditio sine qua non para in-

\footnotetext{
${ }^{41}$ Sobre todo en Los conflictos.... op. cit., p. 360.
} 
terponer el recurso de amparo, pero no es requisito bastante. En todo caso el interés legítimo que ha de concurrir para ejercitar una acción de amparo debe ir acompañado de la intención de reparar una lesión de derechos.

\section{Interés legitimo y titularidad del derecho}

Excluida la legitimación popular para interponer recursos de amparo, dicha legitimación se liga en el texto constitucional con la noción de «interés legítimo» que resulta más amplia que la de titularidad del derecho. En el concepto de interés legítimo se comprende, desde luego, cualquier violación directa del derecho fundamental en el que se funde la petición de amparo por parte de la víctima de la misma, pero también se incluye cualquier interés «en sentido propio, cualificado o específico» (ATC 139/1985).

La determinación, sin embargo, de lo que ha de entenderse por interés legítimo por parte de la jurisprudencia constitucional no puede decirse que haya sido del todo coherente, atendiendo más bien la misma a la necesidad de resolver los problemas concretos que se le planteaban. Así, en supuestos de sucesión procesal se ha rechazado a veces la legitimación del sucesor dado el peculiar carácter de los derechos fundamentales y la inexistencia de un interés propio de éste.

Ha habido casos, sin embargo, en los que el TC se ha mostrado especialmente receptivo a la legitimación de quien en principio resultaba dudoso que pudiera demostrarla como en el supuesto en el que aceptó la de un miembro de un colectivo para recurrir frente a una lesión de derechos del colectivo sin personalidad (STC 214/1991; admisión de la legitimación de una superviviente de un campo de concentración para defender el derecho al honor del pueblo judío).

Respecto a las asociaciones y otros entes colectivos la regla general ha sido la de admitir su capacidad para reaccionar frente a vulneraciones de derechos fundamentales de sus miembros o afiliados, con la única exclusión de las situaciones subjetivas personalísimas de los mismos.

\section{Extranjeros}

Las referencias al concepto de «ciudadano» de algunos artículos de la CE (art. 53.2) y de la LOTC (art. 41.1) podrían haber conducido a pensar que el recurso de amparo se encontraría limitado a los que ostentaran la condición de nacionales españoles, pero la interpretación de estas normas por la jurisprudencia 
constitucional va más bien en el sentido de identificar ciudadano con persona natural, y no con nacional.

Cosa distinta es que hay derechos constitucionales de los que están excluidos los extranjeros por mandato del art. $13 \mathrm{CE}$ y que, lógicamente, no podrán estos invocar ante el TC.

\section{Personas jurídicas. Personas jurídico-públicas}

Ninguna duda cabe de que las personas jurídicas pueden ser titulares de derechos fundamentales y, en cuanto tales, actoras en un recurso de amparo, pero su situación jurídica no es absolutamente equiparable a la de las personas naturales, dado que sus relaciones con los diferentes tipos de derechos fundamentales no son las mismas, al haber algunos que no son predicables de ellas, de modo que, aunque se reconozca a las personas jurídicas la titularidad de algunos derechos, debe tenerse en cuenta que el alcance de estos no tiene por qué ser idéntico al que posea en relación con las personas naturales, lo que incidirá, en su caso, en la legitimación para solicitar su protección.

En cuanto a las personas jurídico-públicas el primer reflejo sería el de excluirlas de la legitimación de un recurso de amparo en el que se pretender proteger derechos ciudadanos, en tanto en cuanto los poderes públicos, en principio, no aparecen como titulares de derechos individuales. Sin embargo la jurisprudencia constitucional española ha aceptado dicha titularidad de manera restrictiva y excepcional, sobre todo respecto de los derechos procesales consagrados en el art. $24 \mathrm{CE}$.

\section{El Ministerio Fiscal}

Ya sabemos que la CE [art. 162.1 b)] reconoce la legitimación para interponer el recurso de amparo, además de a quien ostente un interés legítimo, al Defensor del Pueblo y al Ministerio Fiscal. Es lo que se ha dado en llamar «legitimación institucional». La de este último se deriva de sus funciones reconocidas constitucionalmente de "promover la acción de la justicia en defensa de la legalidad, de los derechos de los ciudadanos y del interés público tutelado por la ley» (art. 124.1 CE).

El dato decisivo, sin embargo, es la escasísima utilización de este mecanismo por el Ministerio Fiscal, probablemente como consecuencia de la amplitud con la que se ha concebido la legitimación ordinaria, que no hace necesaria la intervención del Ministerio Público, sino en muy pocas ocasiones. 


\title{
6. El Defensor del Pueblo
}

También es un caso de legitimación institucional el del Defensor del Pueblo (entre otros art. 29 LODP). La misma se justifica por la especial posición de este órgano en la defensa de los derechos fundamentales (art. $54 \mathrm{CE}$ ). Su uso, sin embargo, ha sido incluso más raro que el de la del Ministerio Fiscal, como consecuencia de que lo ordinario sea la interposición del amparo por los propios afectados, a veces a instancias del propio Defensor del Pueblo que así se lo aconseja tras considerar una queja por ellos presentada.

Title

Problems of standing in constitutional procedures

\section{Summary}

I. introduction. Standing in constitutional procedures; II. The constitutional court as judge of the constitutionality of norms; III. The constitutional court as judge of constitutional conflicts; IV. The constitutional court as judge of fundamental rights

\section{Resumen}

El artículo estudia los problemas de legitimación que se presentan en los diferentes procesos constitucionales, pretendiendo revisar las fallas que el sistema presenta desde la perspectiva de un mejor funcionamiento de los mecanismos previstos por el ordenamiento jurídico español para hacer realidad la plena vigencia del texto constitucional de 1978. Deteniéndose en los diversos procedimientos que pueden residenciarse ante el Tribunal Constitucional en sus diversas capacidades de juez de la constitucionalidad de las normas, tribunal de conflictos y máxima instancia de protección en España de los derechos fundamentales, el autor procede a analizar los pros y los contras de las decisiones tomadas al respecto por el constituyente y el legislador ordinario.

\begin{abstract}
The article studies the problems of standing that can be seen in the different constitutional procedures. Its aim is to review the failures of the system in order to propose a better working of the mechanisms now existing in the legal order of Spain with the intention of making real the enforcement of the Constitution of 1978 . With a detailed exa-
\end{abstract}


mination of the different procedures in which the Constitutional Court acts as judge of the constitutionality of norms, judge of constitutional conflicts, and final judge of fundamental rights, the author examines de goods and problems of the decisions that have been taken in these matters in the Constitution and in the different Acts that have developed it.

\section{Palabras clave}

Legitimación; procesos constitucionales; recurso de inconstitucionalidad; cuestión de constitucionalidad; control de constitucionalidad de tratados; conflictos constitucionales; conflictos de competencia; conflictos entre órganos; conflictos en defensa de la autonomía local; recurso de amparo

\section{Key words}

Standing; constitutional procedures; judicial review of legislation: direct action, constitutionality exception, control of treaties; constitutional conflicts: competence conflicts, conflicts between authorities, conflicts to defend local autonomy; action to defend fundamental rights 